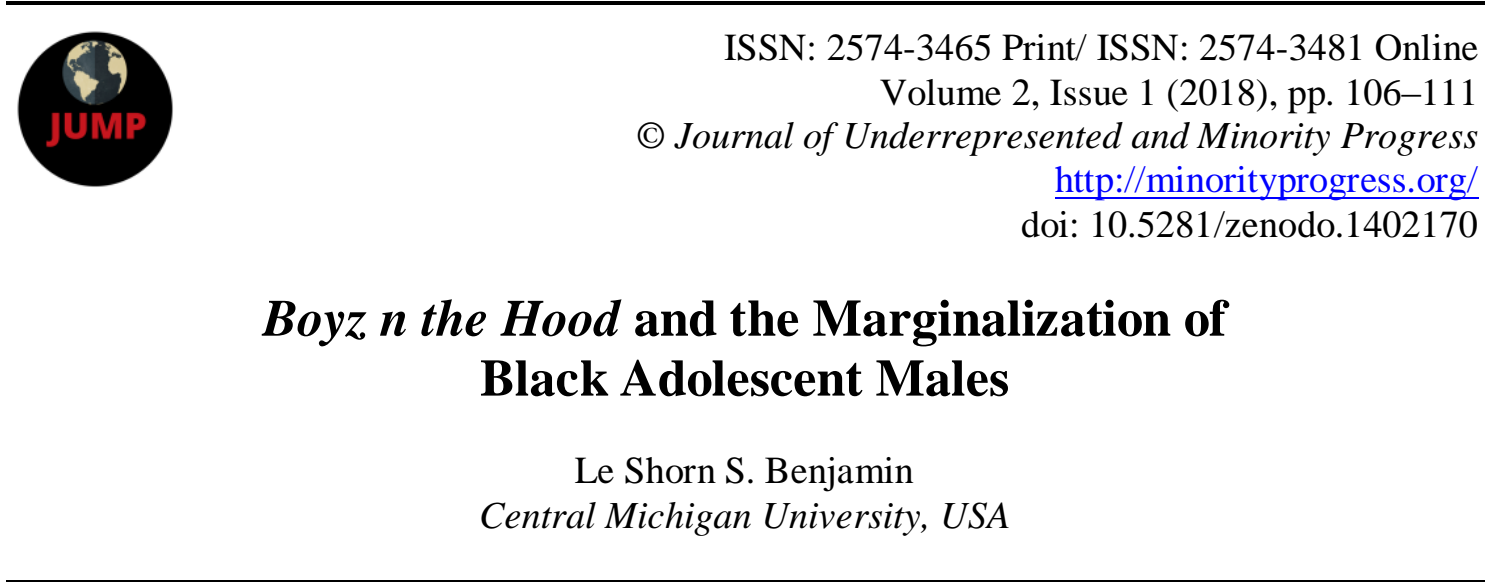

\title{
Boyz $n$ the Hood and the Marginalization of Black Adolescent Males
}

\author{
Central Michigan University, USA
}

\begin{abstract}
John Singleton's Boyz $\mathrm{n}$ the Hood debuted over 25 years ago to critical acclaim and compelling cultural relevance. Underscored by several social justice principles, the film highlights the socioeconomic challenges that ravaged low-income, Black communities during the 80s and early 90s. As a critical examination of Boyz $\mathrm{n}$ the Hood, this film review explores the movie's representation of ineffective policing in black communities; the school-to-prison pipeline for students of color; the shortage of basic necessities for underprivileged children; and the importance of intentional parenting in child development. The article then discusses the implications of these social issues on the Black adolescent males featured in the film and closes with hypothetical solutions for minimizing their marginalized experiences.
\end{abstract}

Keywords: black adolescent males, Critical Race Theory, marginalization, social justice

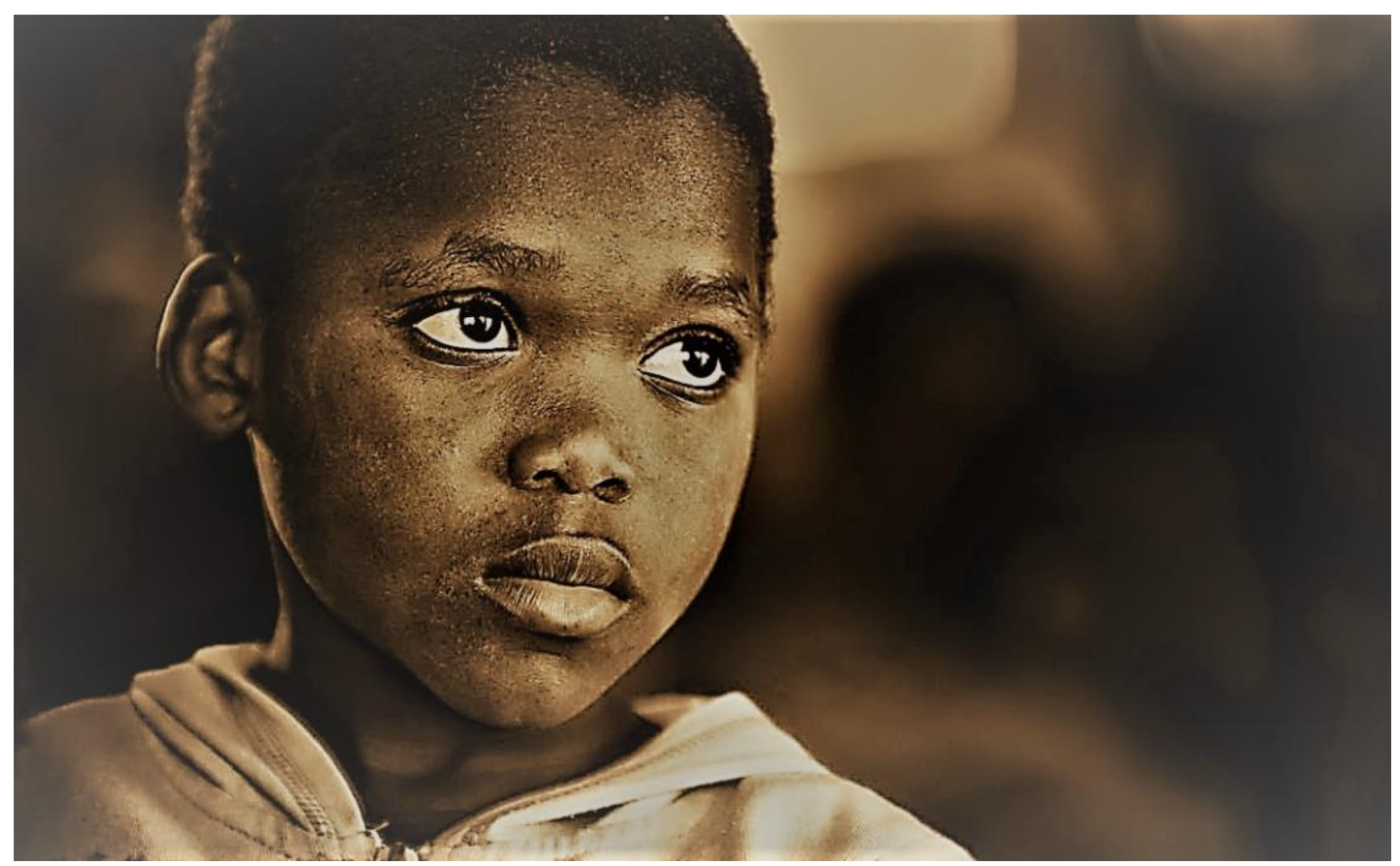

Figure 1. Image of a Black adolescent male representing characters from Boyz $n$ the Hood (Courtesy: pexels.com) 


\section{INTRODUCTION/BACKGROUND}

Set in the violent streets of South Central California, John Singleton's Boyz N the Hood highlights the socioeconomic challenges and degradation which pervaded underprivileged Black communities during the late 1980s and early 1990s. While the movie depicts several issues of concern, namely, ineffective policing in black communities; the school-to-prison pipeline for students of color; the shortage of basic necessities for underprivileged children; and the importance of intentional parenting in child development, this paper specifically examines the implications of these challenges on the Black adolescent males featured in the film. To provide a rounded analysis, the paper closes with hypothetical solutions for minimizing the marginalized experiences portrayed in the movie.

\section{MOVIE SUMMARY}

The movie's opening scene provides a fitting preview of several of the social justice issues which were to unfold. Singleton introduces viewers to the lead actor, Tre, during one of his many classroom hardships. During a teleconference with Tre's mother, Reva, Tre's elementary school teacher discusses his classroom behavior; she acknowledges Tre's extensive vocabulary and his effective articulation but warns the mother of her son's aggressive temper. Immediately, the Caucasian teacher - having begun the conversation with numerous discriminatory assertions questions Tre's African American mother about her occupation and Tre's home life. The biased instructor is visibly surprised to learn that Tre's father plays a significant role in his son's life and that Reva is pursuing graduate studies. After enduring the teacher's blatant discrimination, Tre's mother decides to remove her son from the school and sends him to reside with Furious, his father. Acknowledging Tre's developmental needs and the value of a paternal presence within her son's life, Reva heavy-heartedly entrusts her son into the care of his father. Before departing, she warns Furious of the gravity of his role and urges him to take his duties seriously.

This relocation exposes Tre to the reality and hardships of his newly acquired community but also allows him to develop the skills needed to successfully navigate its disproportionate, socio-economic terrain. Of key significance to the movie's plot is the stark difference between the quantity and quality of parental involvement between Tre and his peers, Ricky and Doughboy. It becomes evident that while Tre benefits from the guidance and supervision of his father, the brothers next door have no interaction with their dad and are short-changed by the negligence of their mom. Along with the differing approaches to parenting in both homes, the boys' varied responses to the challenges of their community, give rise to contrasting outcomes in their adulthood.

\section{THEORETICAL UNDERPINNING}

Given the multiplicity of social ills prevalent in Boyz $n$ the Hood, there is no question that the movie is underscored by several pertinent social justice theories. The film clearly depicts a community that lacks the level of distributive justice needed to ensure the well being of its residents and reveals an over-reliance on retributive principles.

Distributive justice originates from the teachings of philosophical forefathers such as Plato and Socrates and has continued to transform since the era of these canonical writings (Ayers, Quinn \& Stovall, 2009; Jost \& Kay, 2010). Highlighting the scarcity of resources within society, Ayers et al. (2009) explained that distributive justice examines the manner in which limited resources are distributed among a populace. If viewed from the traditional distributive 
justice lens, a society is considered just, if goods and services are allocated equally among all individuals.

Boyz $n$ the Hood illustrates multiple instances where the foundations of distributive justice have collapsed. For example, a scene opens with Furious firing a gunshot at a home intruder; however, the robber dodges the bullet. After calling the police, Furious expresses his concern with the lengthy time taken for officers to respond and notes that a delayed response, such as in that instance, is not the norm in neighboring affluent communities. When the police officers eventually arrive, Furious is astonished by a comment one of the law enforcement agents makes, implying that it was unfortunate that Furious' shot had not resulted in fatality. This statement illustrates the lack of concern for the plight of the victim, as well as the officer's inability to provide effective policing. Sadly, in light of Furious' verbalized suspicions, the officer's behavior and comments provide clear evidence of the unequal distribution of protective services between neighboring communities, and it epitomizes the distributive injustice inherent in the fragile, Black neighborhood.

In a subsequent scene, police officers are seen arresting the two brothers Tre befriended. The boys' arrest is a result of their failed attempt to quell their growing hunger by shoplifting food from a nearby convenience store. This heart-wrenching scene clearly evidences the normalized culture of punitive responses to criminal activity, otherwise known as retributive justice (Grislet, 1991). Gristlet argued that retributive justice favors sentencing policies which give rise to greater imprisonment and decontextualized punishment. Retributive principles provide limited opportunities to "deter" the wrong-doer's proclivity for crime and fails to offer any other rehabilitative options (Grislet, 1991, p. 1). Such harsh legal and judicial responses disproportionately result in the over-criminalization of Black and Brown youth and weaken the fibers of society (Walen, 2016).

The movie then transitions to a later period when the youths are preparing for high school graduation. While Tre and his girlfriend appear settled and well positioned to enter tertiary education, Tre's peers, who were caught shoplifting, have both followed dubious paths. Ricky is now a teenage father, who, despite his opportunity to qualify for an athletic scholarship, is hampered by limited academic prowess and is doubtful of his ability to achieve the minimum required score on the college entrance examination. Doughboy, on the other hand, has continued along a path of crime and has recently been released from yet another stint in prison.

As asserted by Ladson-Billings (2010), Critical Race Theory highlights the normalized nature of racism within American society; the unfavorable outcomes of Tre's childhood friends can possibly be attributed to the racist elements inherent in their community. Specifically, youths of color are more likely to become trapped within the school-to-prison pipeline (Amurao, n.d.) and to underperform on culturally biased standardized tests, such as the SATs (Jencks \& Phillips, 1998). As such, it would be erroneous to decontextualize Ricky and Doughboy's life experiences by disregarding the role their community and parenting have played in their upbringing and outcome. To ignore the factors which have contributed to how the young lads have turned out would be particularly flawed given the inextricable link between social disorganization and criminal activity (Xiong, 2016). Social disorganization theory contends that a community will suffer the consequences (Queen, 1941) of criminal activity and poor literacy (Xiong, 2016), if its stakeholders are unable to provide the social and physical infrastructure needed for the personal growth and development of its residents. 


\section{STAKEHOLDERS AND SOLUTIONS}

By showcasing and integrating the experiences of multiple stakeholders, Boyz $n$ the Hood distinctly portrays the differing - and sometimes dissenting - interests of the community's law enforcement, residential, political, and educational arms. Since each of these constituents exhibit varying levels of engagement and dedication to the proliferation of the community, hypothetically, it would augur better for the stakeholders most affected by the ills of the society to strive towards mitigating these hardships. Although the deleterious effects of limited socioeconomic resources have crippled the South-Central neighborhood depicted in the movie, the indigenous assets of the community should not be ignored. By utilizing and integrating local assets into the improvement efforts, residents can initiate a community-driven style of development (Binswanger, de Regt, \& Spector, 2010), which has the potential to increase the coffer of social capital contained within the neighborhood (Nguyen \& Rieger, 2017).

Achieving this aim is possible through multiple strategies. Firstly, the parents, guardians and adults in the neighborhood can advocate for more culturally relevant curriculum in neighborhood schools. This curricular change will facilitate greater personal investment from students, which can result in better preparation for high-stakes testing. Additionally, the adult residents can form a neighborhood-watch committee to lessen criminal activity within the neighborhood and minimize the entry of neighborhood children into criminal lifestyles. Finally, recognizing that key stages of the movie are set within the summer vacation, it is obvious that Ricky and Doughboy's premature incarceration could have been prevented, if they were involved in a summer enrichment program that provided sufficient meals and activities to occupy their time.

Unfortunately, it can be particularly challenging for residents of a high crime area to develop and execute the proactive responses needed to increase civic engagement in their community (Pancer, 2015). Forming a neighborhood-watch program or spearheading pertinent curricular changes requires sustained commitment, participation, and technical skill, the absence of which can impede improvement efforts. Alternatively, by organizing or lobbying for a community summer enrichment program, residents can provide students with the opportunity to remain engaged and occupied over extended school vacations. Research has shown that summer enrichment programs produce benefits in the short and long run and facilitate students' academic and socio-emotional development (Augustine, McCombs, Pane, Schwartz, Schweig, McEachin, $\&$ Siler-Evans, 2016). These opportunities divert students from deviant behaviors which often lead to criminal activity during fallow periods.

\section{CONCLUSIONS}

Even though Boyz $n$ the Hood debuted over two and a half decades ago, there are various contemporary examples and bodies of research that suggest communities and society continue to marginalize Black adolescent males. As recently as last week, a White Michigan resident opened fire on a Black adolescent male student who, after missing the bus, had stopped to ask for directions to school (Fortin, 2018). Similarly, in a recently published study, using longitudinal data on 20 million American children, Chetty, Hendren, Jones, and Porter (2018) suggested that black boys fare worse than their White counterparts, even when raised in comparably wealthier families. Reporting on the study, Badger, Miller, Pearce, and Quealy (2018) noted that while "most white boys raised in wealthy families will stay rich or upper middle class as adults ... black boys raised in similarly rich households will not" (para. 2). Based on these findings, Badger et. al have also speculated that much of what matters to the development of Black male 
adolescents exists within their neighborhood, the economy, and their societies and have further highlighted that many of these entities view "black boys differently from white boys, and even from black girls" (para. 11).

In addition, empirical research has supported the use of summer enrichment programs in combatting several of the marginalized experiences and outcomes (Mainieri, 2013) that Chetty et. al (2018) highlighted. Understanding that structured summer programs have the potential to produce more civic minded youths, who are capable of contributing social capital to their communities, further highlights the long-term benefits and importance of such initiatives within the context of underserved neighborhoods. Undoubtedly, culturally relevant films like John Singleton's Boyz N the Hood, have provided - and continue to provide - a fitting backdrop for analyzing the current and past experiences of marginalized young Black men. It is hoped, however, that in the next two and half decades, these depictions will only represent artifacts of the systemic and societal forces which previously marginalized, criminalized, and sadly, even dehumanized the existence of countless Black boys in our (neighbor)hoods.

\section{REFERENCES}

Amurao, C. (n.d). Fact sheet: How bad is the school-to-prison pipeline? Retrieved from http://www.pbs.org/wnet/tavissmiley/tsr/education-under-arrest/school-to-prison-pipeline-factsheet/

Augustine, C. H., McCombs, J. S., Pane, J. F., Schwartz, H. L., Schweig, J. D., McEachin, A., \& SilerEvans, K. (2016). Learning from summer: Effects of voluntary summer learning programs on low-income urban youth. Santa Monica, CA: RAND.

Ayers, W., Quinn, T., \& Stovall, D. (2009). Handbook of social justice in education. New York: Routledge.

Binswanger, H. P., de Regt, J. P., \& Spector, S. (2010). Local and community driven development: Moving to scale in theory and practice. Washington, DC: World Bank.

Bourdieu, P. (1986) The forms of capital. In J. Richardson (Ed.), Handbook of theory and research for the sociology of education (pp. 241-258). New York: Greenwood.

Fontin, J. (2018, April 14). A black teenager asked for directions. New York Times. Retrieved from https://www.nytimes.com/2018/04/14/us/michigan-teen-shot-directions.html

Griset, P. L. (1991). Determinate sentencing: The promise and the reality of retributive justice (SUNY series in critical issues in criminal justice). Albany, NY: State University of New York Press.

Jencks, C., \& Phillips, M. (1998). The Black-White test score gap. Washington, D.C.: Brookings.

Jost, J., \& Kay, A. C. (2010). Social justice: History, theory, and research. In S. T. Fiske, D. Gilbert, \& G. Lindzey (Eds.), Handbook of social psychology (5th ed., Vol. 2, pp. 1122-1165). Hoboken, NJ: Wiley.

Ladson-Billings, G. (1998). Just what is critical race theory and what's it doing in a nice field like education? International Journal of Qualitative Studies in Education, 11:1, 7-24.

Mainieri, T. (2013). There was more out there than our street: Exploring a structured summer camp curriculum as an avenue to fostering civic engagement and social capital (Doctoral dissertation). Retrieved from All Dissertations. (Paper 1469).

Nguyen, T., \& Rieger, M. (2017). Community-driven development and social capital: Evidence from Morocco. World Development, 91, 28-45.

Nicolaides, S. (Producer), \& Singleton, J. (Director). (July 2, 1991). Boyz $n$ the Hood [Motion picture]. USA: Columbia.

Pancer, S. M. (2015). The psychology of citizenship and civic engagement. Oxford, GB: Oxford University.

Queen, S. (1941). The concepts social disorganization and social participation. American Sociological Review, 6(3), 307-319. Retrieved from http://www.jstor.org/stable/2086188

Walen, A. (2016). Retributive Justice. Retrieved from https://plato.stanford.edu/archives/win2016/ entries/justice-retributive/ 
Xiong, H. (2016). Urban crime and social disorganization in China: A case study of three communities in Guangzhou. Singapore: Springer.

LE SHORN S. BENJAMIN, M.S.Ed., is an Educational Leadership doctoral student at Central Michigan University. Her research explores marginalized experiences of underrepresented minorities and the career pathways of Ph.D. degree holders. Email: benja1L@cmich.edu

Manuscript submitted: March 3, 2018 Manuscript revised: April 21, 2018 Accepted for publication: May 5, 2018 